\title{
Mesozoic mass extinctions and angiosperm radiation: does the molecular clock tell something new?
}

\author{
Dmitry A. Ruban \\ Division of Mineralogy and Petrography, Geology and Geography Faculty, Southern Federal University, \\ Zorge Street 40, Rostov-na-Donu, 344090, Russian Federation; postal address: P.O. Box 7333, Rostov-na-Donu, 344056, \\ Russian Federation; e-mail: ruban-d@mail.ru
}

\begin{abstract}
Angiosperms evolved rapidly in the late Mesozoic. Data from the genetic-based approach called 'molecular clock' permit an evaluation of the radiation of flowering plants through geological time and of the possible influences of Mesozoic mass extinctions. A total of 261 divergence ages of angiosperm families are considered. The radiation of flowering plants peaked in the Albian, early Campanian, and Maastrichtian. From the three late Mesozoic mass extinctions (Jurassic/Cretaceous, Cenomanian/Turonian, and Cretaceous/Palaeogene), only the Cretaceous/Palaeogene event coincided with a significant, abrupt, and long-term decline in angiosperm radiation. If their link will be further proven, this means that global-scale environmental perturbation precluded from many innovations in the development of plants. This decline was, however, not unprecedented in the history of the angiosperms. The implication of data from the molecular clock for evolutionary reconstructions is limited, primarily because this approach deals with only extant lineages.
\end{abstract}

Keywords: angiosperms, radiation, mass extinction, molecular clock, Mesozoic

\section{Introduction}

The origin and early evolution of angiosperm plants remains a hotly debated subject (Moldowan et al., 1984; Crane, 1987; Martin et al., 1989; Hughes, 1994; Crane et al., 1996; Philippe et al., 1999, 2008; Friis et al., 2003; Feild et al., 2004; Heimhofer et al., 2005, 2007; Soltis et al., 2005; Magallón \& Costello, 2009; Archangelsky et al., 2009; Dilcher, 2010). When their development since the Mesozoic is examined conventionally (such as by, among others, Heimhofer et al., 2005, 2007; Archangelsky et al., 2009; Magallón in Hedges \& Kumar, 2009; Dilcher, 2010), biogeochemical evidence (the presence of oleanane) suggests Late Palaeozoic 'roots' (Taylor et al., 2006). Both intrinsic (evo- lutionary) and extrinsic (environmental) factors were responsible for the angiosperm evolution (e.g., Russell, 2009). One particular question is whether any known mass extinction (Raup \& Sepkoski, 1982; Sepkoski, 1986; Sepkoski \& Raup, 1986; Hallam \& Wignall, 1997) affected the Mesozoic radiation of angiosperms (e.g., McElwain \& Punyasena, 2007).

Genetic studies of extant organisms, including flowering plants, have provided a new powerful approach, called 'molecular clock', which permits to reveal phylogenies and to estimate the time of lineage divergences on the basis of analyses of DNA and protein sequences from present-day life forms (Smith \& Peterson, 2002; Hedges \& Kumar, 2009; Magallón \& Costello, 2009; Quental \& Marshall, 2010). Generally, the 
molecular-clock approach is a combination of biochemical (including genetic) and statistical state-of-the-art techniques, which are focused on possibly neutral mutations occurring stochastically (at least, this is supposed to be so). The recent synthetic volume edited by Hedges \& Kumar (2009) is among the most 'fresh' and extensive sources of data obtained with the above-mentioned approach. In the present viewpoint, I want to discuss whether these data are important for answering the above question about influences of the Mesozoic mass extinctions on the angiosperm evolution. It should be emphasized here, however, that this is not an attempt to promote the genetic-based approach in fossil diversity studies as better than the classical approach, or to present an alternative description of the early angiosperm evolution. The objective of the present contribution is just to find out whether the usage of molecular-clock data can be useful for specialists studying critical transitions in the history of plants in a 'classical' way.

\section{Material and method}

Results of the molecular-clock analyses of angiosperms have recently been summarized by Hedges \& Kumar (2009). Particularly, they summarize the available data on magnoliids (Forest \& Chase, in Hedges \& Kumar, 2009: table 1, p. 168), eudicots (Forest \& Chase, in Hedges \& Kumar, 2009: table 1, pp. 172-173), asterids (Bremer, in Hedges \& Kumar, 2009: table 1, p. 181), eurosids (Forest \& Chase, in Hedges \& Kumar, 2009: table 1, p. 191 and table 1, p. 199), and monocots (Anderson \& Janßen, in Hedges \& Kumar, 2009: table 1, p. 207). Hedges \& Kumar (2009) report a total of 261 divergences at the taxonomic level of families, together with their absolute ages. These data are used for the purpose of the present study. The molecular clock permits to trace divergences of angiosperm extant families back to the Jurassic. I here deal with the time interval of 150-60 Ma in order to embrace the first divergences of angiosperms in the Tithonian and to record the consequences of the end-Cretaceous ecosystem collapse in the early Palaeocene.
The original data presented by Hedges and Kumar (2009) have a moderate resolution, and the divergences are dated with an accuracy of $1 \mathrm{Ma}$. It therefore appears logical to quantify the number of divergences per interval of 1 Ma within the 150-60 Ma interval. The resulting graph then reflects changes in the radiation of ancestors of modern angiosperms with the maximum possible resolution permitted by the available data. These changes are subsequently compared with the available knowledge on mass extinctions. Three mass extinctions are known to have occurred during the 150-60 Ma time interval, namely the Jurassic/Cretaceous, Cenomanian/Turonian, and Cretaceous/Palaeogene mass extinctions. Only the last of these three can be judged as a major event (Raup \& Sepkoski, 1982; Hallam \& Wignall, 1997; Courtillot, 2007; Alvarez, 2008), whereas the two earlier mass extinctions were minor events with a somewhat questionable spatial extent and strength (Hallam, 1986; Hallam \& Wignall, 1997; Harries \& Little, 1999; Smith, 2001; Smith et al., 2001).

The above-mentioned comparison aims at answering two important questions: (1) were these mass extinctions associated with any prominent changes in the radiation of angiosperms, and, if so, (2) what were the links? Two alternative hypotheses can be imagined: if mass extinctions affected angiosperms, they either reduced their ability to radiate at postextinction intervals, or they offered opportunities for innovation, thus accelerating the radiation of flowering plants.

\section{Results}

The angiosperm radiation changed strongly during the 150-60 Ma time interval (Fig. 1). Divergences before the Barremian (before $130 \mathrm{Ma}$ ) weresporadic, but later they became both numerous and frequent. The first peak in angiosperm radiation was reached in the Albian (112-99.6 Ma). Particularly, 9 divergences occurred at 107 $\mathrm{Ma}$, which is an absolute maximum for the Mesozoic. However, the radiation did not remain stable during the Albian, because the number of divergences fell for $2 \mathrm{Ma}$ in the second part of this 


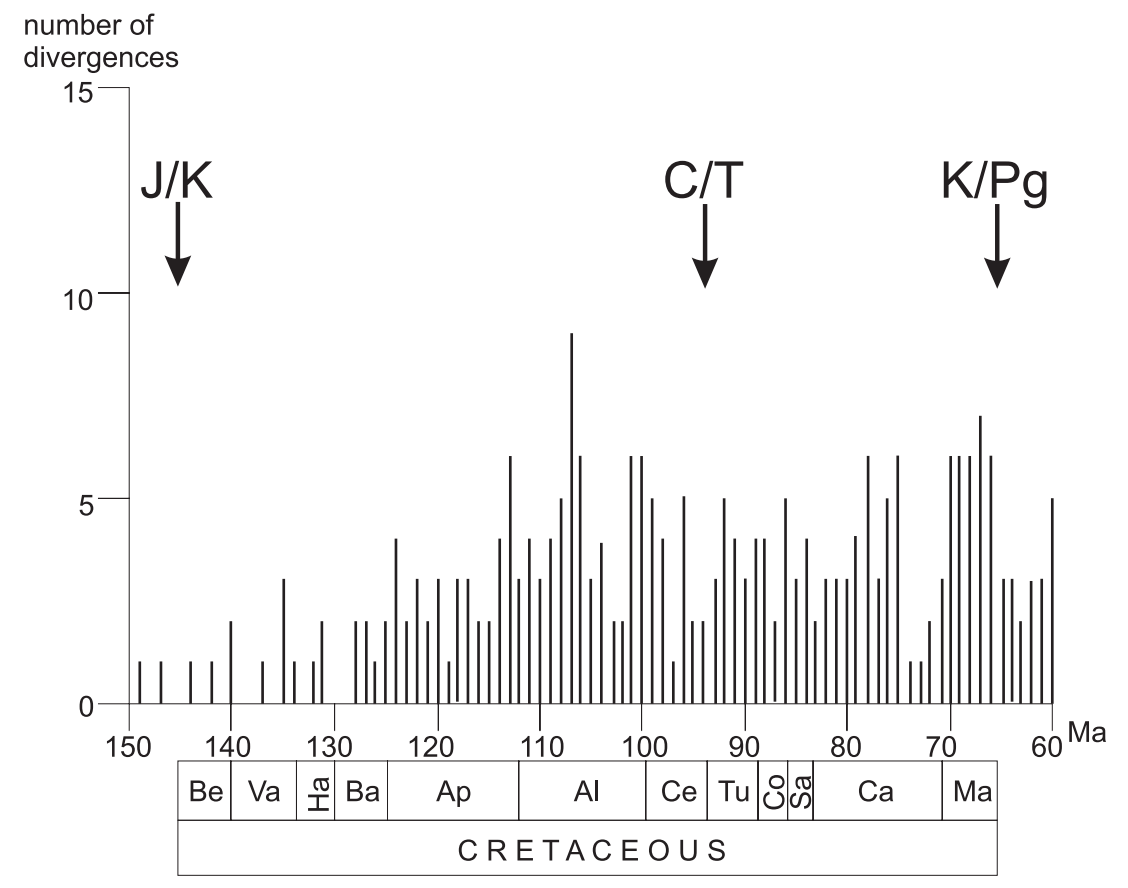

stage. In the early Late Cretaceous, the intensity of radiation declined slightly, and then it fluctuated around the same level. New peaks were reached in the early Campanian (83.5-70.6 Ma) and the Maastrichtian (70.6-65.5 Ma). The latter stage was characterised by a permanently high rate of origination of lineages. Speaking generally, the fluctuating radiation of angiosperms was superimposed by the above peaks, which is in agreement with the idea of punctuated equilibrium (Eldredge \& Gould, 1972; Prothero, 1992; Ivany \& Schopf, 1996; Gould, 2002, 2007). In the time-span under study, only one evident and relatively long-term interruption occurred, viz. in the late Campanian (Fig.1).

It appears that the Jurassic/Cretaceous mass extinction did not affect the angiosperm radiation, which remained the same during the post-extinction interval as before (Fig. 1). In contrast, a decline in intensity occurred at the time of the Cenomanian/Turonian event, although this decline had a short duration and was largely comparable to those that occurred earlier and later and that were not linked with any mass extinction (Fig. 1). Moreover, the radiation intensity had already declined well before the mass extinction.

The Cretaceous/Palaeogene mass extinction was followed by a strong reduction in the radiation intensity, which occurred abruptly
(Fig. 1). The number of family divergences after this catastrophe was about half of the number before this extinction, and this lasted for several millions of years. This interruption is, however, not unique. Its strength and duration are well comparable with those of interruptions that occurred in the late Albian or the late Campanian. If it was the Cretaceous/ Palaeogene mass extinction which reduced the angiosperm radiation in the early Palaeocene, this disaster did not create an opportunity for an increase in evolutionary innovations. The environmental perturbations which affected the terrestrial vegetation at the Cretaceous/ Palaeogene boundary (Tshudy \& Tshudy, 1986; Vajda et al., 2001; Wilf \& Johnson, 2004; McElwain \& Panyasena, 2007; Vajda \& McLoughlin, 2007) probably suppressed the appearance of new lineages of flowering plants for some time. This observation resembles some very recent conclusions on the role of the Cretaceous / Palaeogene mass extinction in the evolution of terrestrial mammals, but those conclusions are far from to be final (Meredith et al., 2011).

\section{Discussion}

The analysis of the Mesozoic radiation of angiosperms raises three questions: (1) how 
realistic are the interpretations of the present study, (2) how different are the results of the present study from those obtained earlier with the same molecular-clock approach, and (3) how well do the results and the interpretations of the present study match those obtained with field-based palaeobotanical data?

Interpretations like those presented here have been attempted earlier for the entire biota (Hedges \& Kumar, 2009) as well as for particular fossil groups (e.g., Medlin et al., 2008). All these studies face, however, one significant limitation: genetic information used by the molecular-clock approach is based on extant organisms only. The reconstruction of fossil diversity or radiation on the basis of genetic phylogenies remains therefore incomplete as the lack of data from extinct lineages cannot be taken into account (Quental \& Marshall, 2010). This problem cannot be solved without further involvement of data on fossils.

The present study suggests that the Cretaceous/Palaeogene mass extinction affected the radiation of angiosperms. This conclusion is more or less true only, however, for the radiation of extant lineages. It cannot be excluded that further consideration of extinct lineages will lead to a stronger or, in contrast, a less outspoken effect. If there were many lineages which appeared just after the Cretaceous/ Palaeogene boundary, but went extinct somewhere in the Cenozoic, their number might be enough to compensate for the losses in the radiation registered with extant lineages only. On the other hand, a decrease in the radiation of extant flowering plants as a result of this mass extinction would, if proven, be interesting because it could reflect the 'invisible' mechanisms of plant/environment interactions at critical transitions. In other words, if the molecular clock provides more or less clear evidence of the influence of any mass extinction on the radiation of extant lineages, this might be interpreted as putting some flowering plants under stress because of the catastrophe, but this would not imply direct evidence of a total reduction of radiation (i.e., of both extant and extinct lineages).

The present study deals only with familylevel lineages. This raises two additional prob- lems. First, it is impossible to be certain that the documented patterns are relevant to the angiosperm evolution at the level of species or even genera. Second, suprageneric taxa are realistic taxa only in 'ideal' cases, but actually they are sometimes artificial. In other words, it is always uncertain that high-ranked taxa have been established properly. Both problems are significant, but, unfortunately, inevitable. Even if the first problem could be solved in the future with special studies aimed at species and genera, the second problem still could not be totally avoided. A plausible solution might be an estimation of the possible error induced by incorrect designations of suprageneric taxa.

In short, the results of any palaeobiological interpretation of molecular-clock data should be regarded with caution, viz. as only an additional - although new and important - piece of evidence. Caution is also required because of a large possible error in the absolute dating of divergences by means of the molecular clock. Although such errors are not indicated for all divergences listed in the work by Hedges and Kumar (2009), and although they are presented in different ways by the various contributors to this work (see the 'Material and method' section for more details about the original data sources), the information available there permits to conclude that the maximum errors can reach $10 \mathrm{Ma}$. For instance, Forest and Chase (table 1, p. 172, in Hedges \& Kumar, 2009) indicate that the divergence of Berberidaceae and Ranunculaceae occurred between 90 and 78 $\mathrm{Ma}$ (with a mean age of $84 \mathrm{Ma}$ ).

Magallón \& Costello (2009) used the molecular-clock approach in order to examine the angiosperm diversification at the level of orders. Their results suggest that modern orders appeared within the Barremian to early Campanian interval. This is consistent with the results of the present study, which indicates a high number of family-level divergences during the same time interval (Fig. 1). However, the data of Magallón \& Costello (2009) permit neither to trace the Maastrichtian radiation nor the effect of the Cretaceous/Palaeogene mass extinction, which two aspects are considered here. Magallón also contributed to the volume edited by Hedges \& Kumar (2009, pp. 161-165), 
and shows that major lineages of angiosperms appeared in the Jurassic.

Field-based palaeobotanical assessments of angiosperm radiation remain fairly scarce. A realistic - although, probably, somewhat outdated - reconstruction of the angiosperm diversity through the Cretaceous has been made by Crane (1987) and was repeated by Anderson et al. (1999). The curve indicates a rapid but steady diversification of angiosperms during the Cenomanian-Campanian time interval and an acceleration of this process in the Maastrichtian. The latter is in agreement with the observation of numerous and frequent divergences of flowering plants during this stage (Fig. 1). There is no evidence from the curve found by Crane (1987) and Anderson et al. (1999) that Mesozoic flowering plants suffered from either a major or a minor mass extinction. It should be mentioned here, however, that the reconstruction by Crane (1987) and Anderson et al. (1999) depicts the total diversity dynamics, but not the rate of origination, that is the intensity of radiation.

\section{Conclusions}

The data produced by the new genetic (molecular-clock) approach are interesting because of two aspects concerning the late Mesozoic evolution of the flowering plants. First, the radiation of angiosperms during the Mesozoic was not gradual but took place in the form of a series of pulses. Second, the only Mesozoic mass extinction which might have had a distinct impact on the number of newly originating angiosperm families was the Cretaceous/ Palaeogene catastrophe, which was followed by a strong decline in the intensity of radiation. The post-extinction radiation decline was, however, not unprecedented.

All observations made in the present contribution are preliminary with regard to the limitations that interpretations based on the molecular clock are presumed to have. Future studies should therefore pay much attention to - if not focus mainly on - the calibration of the molecular-clock results with palaeobotanical data and the creation of a solid basis for realis- tic interpretations of the information obtained through such innovative approaches as the molecular clock.

\section{Acknowledgements}

The author gratefully thanks the reviewers for constructive criticism and useful suggestions and A.J. van Loon (Poland/Netherlands) for his linguistic editing of the text. The help with literature provided by G.G. Puebla (Argentina), W. Riegraf (Germany), and I.Yu. Safonova (Russia) as well as explanations on the possible Palaeozoic origin of angiosperms by $\mathrm{H}$. Li (U.S.A.) are appreciated.

\section{References}

Alvarez, W., 2008. T. rex and the Crater of Doom - the story that waited 65 million years to be told - how a giant impact killed the dinosaurs, and how the crater was discovered. Princeton University Press (Princeton), 185 pp.

Anderson, J.M., Anderson, H.M., Archangelsky, S., Bamford, M., Chandra, S., Dettemann, M., Hill, R., McLoughlin, S. \& Rössler, O., 1999. Patterns of Gondwana plant colonisation and diversification. Journal of African Earth Sciences 28, 145-167.

Archangelsky, S., Barreda, V., Passalia, M.G., Gandolfo, M., Prámparo, M., Romeroa, E., Cúneo, R., Zamuner, A., Iglesias, A., Llorens, M., Puebla, G.G., Quattrocchio, M. \& Volkheimer, W., 2009. Early angiosperm diversification: evidence from southern South America. Cretaceous Research 30, 1073-1082.

Courtillot, V., 2007. Evolutionary catastrophes - the science of mass extinction. Cambridge University Press (Cambridge), $173 \mathrm{pp}$.

Crane, P.R., 1987. Vegetational consequences of the angiosperm diversification. [In:] E.M. Friis, W.G. Chaloner \& P.R. Crane (Eds): The origins of angiosperms and their biological consequences. Cambridge University Press (Cambridge), 181-201.

Crane P.R., Friis, E.M. \& Pedersen, K.P., 1996. The origin and early diversification of angiosperms. Nature 374, 27-33.

Dilcher, D., 2010. Major innovations in angiosperm evolution. [In:] C.T. Gee (Ed.): Plants in Mesozoic time morphological innovations, phylogeny, ecosystems. Indiana University Press (Bloomington), 97-116.

Eldredge, N. \& Gould, S.J., 1972. Punctuated equilibria: an alternative to phyletic gradualism. [In:] T.J.M. Schoft (Ed.): Models in paleobiology. Freeman Cooper (San Francisco), 82-115.

Feild, T.S., Arens, N.C., Doyle, J.A., Dawson, T.E. \& Donoghue, M.J., 2004. Dark and disturbed: a new image of early angiosperm ecology. Paleobiology 30, 82-107.

Friis, E.M., Doyle, J.A., Endress, P.K. \& Leng, Q., 2003. Archaefructus: angiosperm precursor or specialized early angiosperm? Trends in Plant Science 8, 369-373. 
Gould, S.J., 2002. The structure of evolutionary theory. Belknap Press (Cambridge), 1433 pp.

Gould, S.J., 2007. Punctuated equilibrium. Belknap Press (Cambridge), 396 pp.

Hallam, A., 1986. The Pliensbachian and Tithonian extinction events. Nature 319, 765-768.

Hallam, A. \& Wignall, P.B., 1997. Mass extinctions and their aftermath. Oxford University Press (Oxford), 320 pp.

Harries, P. \& Little, C.T.S., 1999. The early Toarcian (Early Jurassic) and the Cenomanian-Turonian (Late Cretaceous) mass extinctions: similarities and contrasts. Palaeogeography, Palaeoclimatology, Palaeoecology 154, 39-66.

Hedges, S.B. \& Kumar, S. (Eds), 2009. The timetree of life. Oxford University Press (Oxford), 551 pp.

Heimhofer, U., Hochuli, P.A., Burla, S., Dinis, J.M.L. \& Weissert, H., 2005. Timing of Early Cretaceous angiosperm diversification and possible links to major paleoenvironmental change. Geology 33, 141-144.

Heimhofer, U., Hochuli, P.A., Burla, S. \& Weissert, H., 2007. New records of Early Cretaceous angiosperm pollen from Portuguese coastal deposits: Implications for the timing of the early angiosperm radiation. Review of Palaeobotany and Palynology 144, 39-76.

Hughes, N.F., 1994. The enigma of angiosperm origins. Cambridge Uiversity Press (Cambridge), 303 pp.

Ivany, L.C. \& Schopf, K.M. (Eds), 1996. New perspectives on faunal stability in the fossil record. Palaeogeography, Palaeoclimatology, Palaeoecology 127, 1-359.

Magallón, S. \& Castillo, A., 2009. Angiosperm diversification through time. American Journal of Botany 96, 349-365.

Martin, W., Gierl, A. \& Saedler, H., 1989. Molecular evidence for Pre-Cretaceous angiosperm origins. Nature $339,46-48$.

McElwain, J.C. \& Punyasena, S.W., 2007. Mass extinction events and the plant fossil record. Trends in Ecology $\mathcal{E}$ Evolution 22, 548-557.

Medlin, L.K., Sáez, A.G. \& Young, J.R., 2008. A molecular clock for coccolithophores and implications for selectivity of phytoplankton extinctions across the $\mathrm{K} / \mathrm{T}$ boundary. Marine Micropaleontology 67, 69-86.

Meredith, R.W., Janecka, J.E., Gatesy, J., Ryder, O.A., Fisher, C.A., Teeling, E.C., Goodbla, A., Eizirik, E., Simao, T.L.L., Stadler, T., Rabosky, D.L., Honeycutt, R.L., Flynn, J.J., Ingram, C.M., Steiner, C., Williams, T.L., Robinson, T.J., Burk-Herrick, A., Westerman, M., Ayoub, N.A., Springer, M.S. \& Murphy, W.J., 2011. Impacts of the Cretaceous Terrestrial Revolution and KPg Extinction on Mammal Diversification. Science 334, 521-524.

Moldowan J.M., Dahl, J., Huizinga, B.J., Fago, F.J., Hickey, L.J., Peakman, T.M. \& Taylor, D.W., 1984. The molecular fossil record of oleanane and its relation to Angiosperms. Science 265, 768-771.

Ogg, J.G., Ogg, G. \& Gradstein, F.M., 2008. The concise geologic time scale. Cambridge University Press (Cambridge), 177 pp.

Philippe, M., Barale, G., Gomez, B., Guignard, G. \& Thévenard, F., 1999. Paléodiversifications de flores terrestres phanérozoïques. GeoBios 32, 325-331.

Philippe, M., Gomeza, B., Girard, V., Coiffard, C., Daviero-Gomez, V., Thévenard, F., Billon-Bruyat, J.-P., Gui- omard, M., Latil, J.-L., Le Loeuff, J., Neraudeau, D., Olivero, D. \& Schlögl, J., 2008. Woody or not woody? Evidence for early angiosperm habit from the Early Cretaceous fossil wood record of Europe. Palaeoworld 17, 142-152.

Prothero, D.R., 1992. Punctuated equilibrium at twenty: a paleontological perspective. Skeptic 1, 38-47.

Quental, T. \& Marshall, C.R., 2010. Diversity dynamics: molecular phylogenies need the fossil record. Trends in Ecology \& Evolution 25, 434-441.

Raup, D.W. \& Sepkoski, J.J., 1982. Mass extinctions in the marine fossil record. Science 215, 1501-1503.

Russell, D.A., 2009. Islands in the cosmos - the evolution of life on land. Indiana University Press (Bloomington), $453 \mathrm{pp}$.

Sepkoski, J.J., Jr., 1986. Phanerozoic overview of mass extinctions. [In:] D.M. Raup \& D. Jablonski (Eds): Patterns and processes in the history of life. Springer (Berlin), 277-295.

Sepkoski, J.J., Jr. \& Raup, D.M., 1986. Periodicity in marine extinction events. [In:] D.K. Elliott (Ed.): Dynamics of extinction. John Wiley (New York), 3-36.

Smith, A.B., 2001. Large-scale heterogeneity of the fossil record: implications for Phanerozoic biodiversity studies. Philosophical Transactions of the Royal Society of London B 356, 351-367.

Smith, A.B. \& Peterson, K.J., 2002. Dating the time of origin of major clades: molecular clocks and the fossil record. Annual Review of Earth and Planetary Sciences 30, 65-88.

Smith, A.B., Gale, A.S. \& Monks, N.E.A., 2001. Sea-level change and rock-record bias in the Cretaceous: a problem for extinction and biodiversity studies. Paleobiology 27, 241-253.

Soltis, D.E., Soltis, P.E., Endress, P.K. \& Chase, M.W., 2005. Phylogeny and evolution of angiosperms. Sinauer Associates (Sunderland), $370 \mathrm{pp}$.

Taylor, D.W., Li, H., Dahl, J., Fago, F.J., Zinniker, D. \& Moldowan, J.M., 2006. Biogeochemical evidence for the presence of the angiosperm molecular fossil oleanane Paleozoic and Mesozoic non-angiospermous fossils. Paleobiology 32, 179-190.

Tshudy, R.H. \& Tshudy, B.D., 1986. Extinction and survival of plant life following the Cretaceous/Tertiary boundary event, Western Interior, North America. Geology 14, 667-670.

Vajda, V. \& McLoughlin, S., 2007. Extinction and recovery patterns of the vegetation across the CretaceousPalaeogene boundary - a tool for unravelling the causes of the end-Permian mass-extinction. Review of Palaeobotany and Palynology 144, 99-112.

Vajda, V., Raine, J.I. \& Hollis, C.J., 2001. Indication of global deforestation at the Cretaceous-Tertiary boundary by New Zealand fern spike. Science 294, 1700-1702.

Wilf, P. \& Johnson, K.R., 2004. Land plant extinction at the end of the Cretaceous: a quantitative analysis of the North Dakota megafloral record. Paleobiology 30, 347-368.

Manuscript received: 24 June 2011 Revision accepted: 15 January 2012 